\title{
Increasing Incidence of Thyroid Carcinoma: Risk Factors and Seeking Approaches for Primary Prevention
}

\author{
Valentina Drozd ${ }^{1}$, Daniel I. Branovan ${ }^{2}$ and Christoph Reiners ${ }^{3}$ \\ The International Fund "Help for patients with radiation-induced thyroid cancer 'Arnica'"', Minsk, Belarus, New York Ear, Nose \\ and Throat Institute', New York, NY, United States, Clinic and Policlinic of Nuclear Medicine, University of Würzburg', \\ Würzburg, Germany
}

\begin{abstract}
Based on opinions published by many scientists about the increase in the incidence of thyroid cancer in many countries, this paper intends to identify research to be done on one hand with respect to reasons for this increase, the natural course of thyroid cancer and risk factors and - on the other hand - to support the clinician in primary prevention of thyroid cancer. Along with the traditionally discussed risk factors: ethnicity, heredity, sex effects/hormones, comorbidity, radiation exposure, diet (iodine), life-style (smoking), features of the natural environment, the effect of endocrine disrupters and in particular nitrates are also discussed. For the clinician, a simple approach for primary prevention of thyroid cancer is to refer the patient for a radiological examination applying ionizing radiation with exposure of the head and neck region only if the indication is justified according to the International Committee for Radiological Protection. In clinical practice, it is also important to take into account and minimize other risk factors: prevention of obesity and weight reduction, adequate treatment of various thyroid diseases, avoidance of excessive consumption of nitrates and other endocrine disruptors/ environmental pollutants. In case of a nuclear emergency, attention has to be paid for immediate withdrawal of contaminated food and drink as well as iodine thyroid blocking especially in vulnerable members of the population as children, pregnant or breastfeeding women. More research is also required to identify other reasons of the increasing incidence and predictors of aggressive vs indolent behavior of thyroid cancer to avoid unnecessary screening activity, overdiagnosis, and overtreatment.
\end{abstract}

Key Words: Thyroid carcinoma, Risk factors, Screening, Radiation, Nitrate, Prevention

\section{Introduction}

An increase in thyroid cancer incidence since the late 80 's is higher than in any other cancer. Many studies have demonstrated that screening with ultrasonography is an important occasion contributing to this rise. ${ }^{1-3)}$ The increase of thyroid cancer incidence however may not be completely dependent on screening only. It has to be reviewed that the ex- posure to known and unknown risk factors like radiation, lifestyle changes, and environmental pollutants contribute to the increase of thyroid cancer incidence. It is also believed that overdiagnosis may be a result of thyroid screening activity. Even with generally favorable prognosis, early diagnosis of thyroid cancer and its benefits have been discussed and new clinical approaches for active surveillance of thyroid microcarcinoma are suggested. This paper intends to contribute to this discussion addressing research to be

Received August 3, 2020 / Revised October 1, 2020 / Accepted October 6, 2020

Correspondence: Valentina Drozd, MD, PhD, The International Fund "Help for patients with radiation-induced thyroid cancer

"Arnica”, Minsk, 220005, Zolotaja gorka 11, Belarus

Tel: 375295003355, Fax: 375172909812, E-mail:vm.drozd@gmail.com

Copyright (c) the Korean Thyroid Association. All rights reserved.

(1) \& This is an open-access article distributed under the terms of the Creative Commons Attribution Non-Commercial License (http://creative(c) (1) \& 8 commons.org/licenses/by-nc/4.0/), which permits unrestricted non-commercial use, distribution, and reproduction in any medium, provided the original work is properly cited. 
Risk Factors of Increasing Incidence of Thyroid Carcinoma

done with respect to risk factors for thyroid cancer other than exposure to radiation, the natural course of disease on one hand and to support the clinician in primary prevention of thyroid cancer on the other.

\section{Epidemiology of Differentiated Thyroid Cancer}

Over the last three decades, the incidence rate of thyroid cancer has steadily increased in different regions, ${ }^{4-7)}$ most significantly in South Korea, Italy, France, the United States, and Australia. ${ }^{8-11)}$ The growth rate of thyroid cancer incidence is higher than any other malignant tumor in the United States along with liver cancer. ${ }^{4)}$ According to the study by Lim et al. ${ }^{11)}$ from the Surveillance, Epidemiology and End Results (SEER) program, an average increase in thyroid cancer incidence during 1974-1977 was 4.56 per 100,000 person-years, and significantly higher - 14.42 per 100,000 person-years during 2010-2013. Interestingly, the sharpest increase of annual percent change (APC) with 12.2\% (10.6-13.8\%) was found for papillary thyroid cancer (PTC) with a diameter of less than $1 \mathrm{~cm}$ between 1998 and 2003. However, the incidence of tumors larger than $4 \mathrm{~cm}$ of diameter increased as well (e.g. with an APC increase of $6.9 \%$ (6.2-7.6\%). ${ }^{11)}$ According to incidence data for five continents made available by the WHO International Agency for Research on Cancer in Lyon, ${ }^{12)}$ there are other countries with even steeper increases of thyroid cancer incidence during the last 30 years; among them are Italy and Korea. For Italy, the data originates from smaller local registries in the country and is not comparable to high coverage data as in the US registry. The figures for Korea result from mass screening and will be discussed below in section 3 . The incidence of thyroid cancer after the Chernobyl accident in the past 25 years is increased markedly in Belarus and Ukraine, see section 4.2.

The increase of thyroid cancer incidence among children has been announced in some countries. In the US, the study by Qian et al. ${ }^{13)}$ using the SEER database from 1973 to 2013 among 1806 individuals younger than 20 years reported that the incidence rates of thyroid cancer in this period of time increased from 0.48 to 1.14 per 100,000 person-years. APC was 1.11\%; (95\% confidence interval [Cl], 0.56-1.67\%) from 1973 to 2006 and then substantially enlarged to 9.56\%; (95\% Cl, 5.09-14.22\%) from 2006 to 2013. McNally et al. ${ }^{14)}$ found that in northern England the standardized incidence rates of thyroid cancer rose from 0.2 to 0.6 per million in male aged $0-14$ years from 1976-1986 to 1997-2005, and from 0.3 to 0.5 per million in female children. According to Korea Central Cancer Registry, the crude incidence of pediatric thyroid cancer between 1999-2012 grew from 0.5 to 1.7 per 100,000 and the proportion among different type of cancers increased from $4.4 \%$ to $10.6 \% .{ }^{15)}$

Of note, the difference in autopsy prevalence of thyroid carcinoma (or microcarcinoma) from $0.01 \%$ in USA to $35.6 \%$ in Finland is very high and might be primarily related to methods used for slicing of the thyroid and histological examination. ${ }^{16,17)}$ In a meta-analysis of the prevalence of differentiated thyroid cancer (DTC) with dissection of the whole gland in autopsy studies, the mean prevalence of DTC with $11 \%$ was stable from 1975-2001, however with large fluctuations hampering the interpretation of results. ${ }^{18)}$

\section{Screening and Overdiagnosis}

Many publications have demonstrated that reasons for thyroid cancer incidence rise worldwide are mainly due to expansion in screening and enhancements in diagnostic process for detecting small nodes resulting in "overdiagnosis", meaning that otherwise indolent cancers are identified which would not have caused clinical symptoms or death due to this disease. ${ }^{3,9,10)}$ The American Thyroid Association (ATA) released an updated Guideline in 2015, suggesting screening people with familial follicular cell-derived DTC may contribute to a diagnosis of thyroid cancer at an early stage. However the panel did not recommend "for or against ultrasound screening because there are no proofs of reducing morbidity or mortality". ") The US Preventive Services Task Force (USPSTF) in 2017 stands "against screening for thyroid cancer in asymptomatic adults". ${ }^{2)}$ Clinicians were advised neither to 
use neck palpation nor ultrasonography or other techniques and that the "harm from such screening in asymptomatic persons can outweigh any benefits". In the same time, the USPSTF acknowledges that reasons of increase in the risk for thyroid cancer could be related to preventive medical examinations, a history of radiation exposure, family history of thyroid cancer (familial medullary thyroid cancer or multiple endocrine neoplastic syndrome). ${ }^{2)}$

However, real reasons promoting to the thyroid cancer "epidemic" are more complex, seeming to be multifactorial and the main explications for this increase are still under discussion. Some of them are associated with widespread practice of ultrasound and fine-needle aspiration (FNA) for assessment of small thyroid nodules. The first experience of implementing ultrasound mass screening programs for detection of thyroid cancer was acquired after Chernobyl. The results of this screening will be discussed in sections 4.2 and 5.5 .

The thyroid cancer incidence rose in Korea from 10.6 in 1996 to 111.3 per 100,000 in women in 2010, and it rose from 1.9 to 27.0 per 100,000 in men in the same period of time. The numbers indicate a $25 \%$ annual increase over the past decade after mass screening was introduced in Korea. ${ }^{19)}$ Between 2007 and 2010 the mortality of thyroid cancer was 0.7 per 100,000 people. Screening has been associated with increased diagnosis of thyroid cancer $(r=0.74[95 \% \mathrm{Cl}$, 0.59-0.88]); but was not linked to mortality $(r=-0.08$ [95\% Cl, 0.59-0.63]) due to this disease. ${ }^{20)}$ According to study based on Statistics Korea by Choi et al. ${ }^{211}$ the age-standardized mortality rates (ASMRs) of thyroid cancer elevated from $0.17(95 \% \mathrm{Cl}, 0.17-0.18)$ to 0.85 $(95 \% \mathrm{Cl}, 0.83-0.86)$ per 100,000 in period of time between 1985-2004. It was the highest rate among all countries. Between 2004 and 2015 the ASMRs declined to $0.42(95 \% \mathrm{Cl}, 0.41-0.43)$ per 100,000 . The authors gave estimates of the APC $7.94(95 \% \mathrm{Cl}$, 6.43-9.46) from 1985 to 2004 , and $-4.10(95 \% \mathrm{Cl}$, -5.76 to -2.40 ) between 2004 and 2015. Also the authors believe that some factors like changes in lifestyle, standardization of diagnosis and treatment of thyroid cancer could be related to the decline in thy- roid cancer mortality in Korea. ${ }^{21)}$ Korean multicenter cohort study by Jeon et al. ${ }^{22)}$ demonstrated decreasing disease-specific mortality of DTC in period 2 (20012003) and 3 (2004-2005) compared to that of period 1 (1996-2000). The authors found that the size of the tumors and the portion of high-volume lymph node metastases have become smaller with period of follow-up. ${ }^{22)}$ These findings suggest a possible benefit of early diagnosis of small thyroid cancer.

According to Korea Central Cancer Registry, the crude thyroid cancer incidence among children (0-19 years) from 1999 to 2012 increased 3 times. ${ }^{15)}$ According to Cho et al. ${ }^{15)}$ at Samsung Medical Center between 1995 and 2013, among operated 126 children with thyroid cancer, 91 cases (72\%) were diagnosed by palpation and the only $28 \%$ was identified by imaging studies. Thus, in children, most tumors are detected by palpation, but not by ultrasound.

According to estimates by Vaccarella et al. ${ }^{10)}$ thyroid screening could be related to $60 \%$ or more of all thyroid cancer cases in women diagnosed between 2003-2007 in Italy, France, the United States, the Republic of Korea, and Australia and about $30 \%$ in other high-income countries. Some studies emphasized that thyroid cancer incidence correlated with employment, white-collar jobs, higher household income, education, and health insurance coverage, and other socio-demographic markers such as number of doctors in the area (endocrinologists, surgeons, radiologists). ${ }^{23-25)}$

It should be noted, that application of thyroid ultrasonography and FNA, increased medical surveillance, could not completely elucidate the increase in incidence of PTC because a significant rise was discovered for larger tumors. ${ }^{8,11,26,27)}$ The authors conclude that these findings indicate a real increase in thyroid cancer incidence in the United States, because such large tumors are not "silent" and are not only detectable by ultrasound but will be diagnosed by inspection and palpation of the neck or cause complaints for the patient. In addition, the clinical relevance of such large tumors can be derived from the circumstance, that for this subgroup thyroid cancer related mortality is increasing over time. , $^{811)}$

In regards to the screening effect, Lin et al. ${ }^{28)}$ con- 
Risk Factors of Increasing Incidence of Thyroid Carcinoma

cluded that there are still "no data related to clinical trials that examined the results of screening for morbidity or mortality of thyroid cancer, compared to the absence of screening". Also, there aren't any "data related to the harms of thyroid cancer screening, as well no studies examined the effect of overdiagnosis in a screened versus unscreened populations". According to Jung et al. ${ }^{29)}$ in representative study for thyroid cancer screening in Korea (NEST), 1.1\% of patients died in the screening group compared to $4.1 \%$ in the clinical detection group during follow-up 9.4 years $(p<0.001)$. The authors believe that screening was related to a decrease in mortality in the advanced stage of thyroid cancers, however not in the early stage of the disease.

\section{Radiation as a Well-Known Risk Factor}

\section{Medical Radiation Exposure}

Many studies have demonstrated that different kinds of cancers in children are more likely than in adults to be caused by radiation. Even small doses, less than 50-100 mGy may increase the risk of childhood thyroid cancer, with a linear dose-response up to 10-20 Gy. The excess risk remains after exposure for more than four decades. ${ }^{30-34)}$

External radiotherapy in children for different type of cancer, enlarged thymus and tonsils, tinea capitis might raise the risk of thyroid cancer. ${ }^{30,31,35-37)} \mathrm{An}$ updated pooled analysis of 12 studies by Veiga et al. ${ }^{38)}$ demonstrated a risk model of external radiation doses to the thyroid in children, with relative risks (RR) rising supralinearly through 2-4 Gy, then leveling and decreasing above $30 \mathrm{~Gy}$.

In the United States exposure to medical diagnostic $X$-rays has increased considerably until 2006, from an estimated mean per capita effective dose of $0.54 \mathrm{mSv}$ (1980) to $3.0 \mathrm{mSv}$ (2006) and then decreased slightly to $2.3 \mathrm{mSv}$ (2016). The frequency of computerized tomography (CT) scans, nuclear medicine examinations and other radiologic procedures grew about 10-fold between 1950-2006, accounting to about 50\% of increased exposure. ${ }^{39-41)}$ In Germany the estimated mean per capita of "medical" effective dose is increasing as well and in 2014 reached $1.6 \mathrm{mSv}$. The application frequency of CT scans was $9 \%$, however CT contributed $1 \mathrm{mSv}(=62 \%)$ to the increasing per capita dose from all sources. ${ }^{42)}$

To give an estimate of the radiation risk for the thyroid involved with $\mathrm{CT}$, it is more appropriate to focus on organ doses instead on effective doses. The dose to the thyroid involved with neck CT may reach up to 80 mGy. ${ }^{43-55)}$ Modern CT techniques with e.g. automatic tube current modulation and the thyroid bismuth shielding may mitigate thyroid doses by $40-80 \% .{ }^{43-45)}$ For cerebral angiography, thyroid doses as high as 250 mGy are reported. ${ }^{46)}$ The use of CT with iodinated contrast enlarges the radiation-absorbed dose by the thyroid gland by up to $35 \%{ }^{47)}$ A population based case-control study by Zhang et al ${ }^{48)}$ provides first accurate evidence that nuclear medicine procedures and CT scans may be responsible for an increased risk of thyroid cancer in adults. According to Zhang et al. ${ }^{48)}$ any type of diagnostic radiography was associated with an increased risk of tumor size $\leq 10 \mathrm{~mm}$, (odds ratio $[\mathrm{OR}]=2.76,95 \% \mathrm{Cl}, 1.31-5.81)$. The authors concluded that in the US population $37-85 \%$ of well-differentiated thyroid microcarcinomas could be linked to medical radiation exposure. ${ }^{48)}$ The weakness of Zhang's study is that the information on diagnostic X-ray exposures was collected on self-reporting. A recent massive study of 12 million youths in Korea also raises troubling questions about the increased thyroid cancer risk (IRR, 2.19 [95\% Cl, 1.97-2.20]) at very low doses of radioactivity during diagnostic procedures. ${ }^{49)}$

In several publications, dental $X$-ray examinations have been linked to an increased thyroid cancer risk ${ }^{50,51)}$ and tumors of the parotid gland as well. ${ }^{52,53)}$ An increased risk of thyroid cancer has been described in diagnostic X-ray workers, dentist's assistants, and radiology technicians. ${ }^{54,55)}$ The case-control study by Memon et al. ${ }^{50)}$ found that self-reported dental $X$-ray examinations (particularly multiple) were significantly associated with the risk of thyroid cancer $(\mathrm{OR}=2.1$, $95 \% \mathrm{Cl}, 1.4-3.1, p<0.001)$. In this regard, recommendations by the American Dental Association stress the requirement "for shielding of the thyroid during 
dental X-ray" examination. ${ }^{56)}$ The results of recent meta-analysis by Han and $\mathrm{Kim}^{57)}$ indicate that diagnostic radiation exposure is associated with an increased thyroid cancer risk: for overall exposure to diagnostic radiation exposure ( $\mathrm{OR}=1.52$ [Cl 1.13-2.04]); by type of exposure, exposure to computed tomography scans $(\mathrm{OR}=1.46[\mathrm{Cl} 1.27-1.68])$, dental $X$-rays $(\mathrm{OR}=1.69[\mathrm{Cl} 1.17-2.44])$, head and neck $(\mathrm{OR}=1.31 \mathrm{Cl}$ 1.02-1.69]) and chest (OR=1.71 [Cl 1.09-2.69]).

\section{Radiation Exposure from Atomic Bombing, Nuclear Accidents and from Nuclear Facilities in the Past}

Numerous studies indicated the serious health consequences of the atomic bombing in Hiroshima, Nagasaki, Nevada, Marshall Islands, Semipalatinsk, Nowaja Semlja. ${ }^{58-61)}$ Thyroid cancer was among the first solid cancers that arose after the atomic bombing in Japan. ${ }^{59,60)}$ The highest risk of thyroid cancer was among of atomic bombs survivors in Hiroshima and Nagasaki younger than 10 years old, in the older subjects the risk was considerably smaller. ${ }^{61)}$

The consequences of exposure from fallout after the Russian nuclear tests in Nowaja Semlja and the incidence of thyroid cancer were studied in Norway and Sweden by Lund and Galanti. ${ }^{62)}$ The authors found that the RR of developing thyroid cancer was higher for exposed cohorts (born 1951-1962), compared to ones not exposed (born 1963-1970).

According to WHO experts, the most serious long-term consequences of the Chernobyl in Belarus, Ukraine and Russia were about 11,000 thyroid cancers cases among those who were exposed to radiation in childhood at the time of the accident. ${ }^{63,64)}$ The number of pediatric thyroid cancer in Belarus began to increase dramatically around four years after the Chernobyl accident. ${ }^{65,66)}$ Ecological studies in Ukraine and Belarus found that thyroid cancer risk after the Chernobyl estimated a linear excess relative risk (ERR)/Gy of 18.9 and excess absolute risk (EAR) per Gy per person year of 2.66. ${ }^{67-69)}$ Case-control studies in Belarus and Russia among exposed children with individual thyroid dose estimates of 1311 reported ERR per Gy between 4.2 and $7.2 .^{70,71)}$ Cohort studies based on individual thyroid dose estimates published ERR/Gy of 5.25 for thyroid cancer in Ukraine ${ }^{72,73)}$ and 2.15 for Belarus. ${ }^{74,75)}$ Many post-Chernobyl studies detected the rising thyroid cancer risk with declining age at ${ }^{131}$ | exposure. ${ }^{69,76)}$ An international consensus found, the risk of radiation induced thyroid cancer substantially increases at doses more than $100 \mathrm{mSv}^{7,77,78)}$

Some studies support an association between residence in the proximity to nuclear power plant (NPP) or an exposure event from one of the nuclear reactors in the United States and the incidence of thyroid cancer. ${ }^{79,80)}$ According to a study of individuals residing near NPP in France, the thyroid cancer incidence was comparable to control groups. ${ }^{81)}$ The study of Davis et al. ${ }^{82)}$ gave no arguments, that the release of 131-iodine from the Hanford site (USA) increased the incidence of thyroid cancer. A meta-analysis of epidemiologic studies was conducted by Kim et al. ${ }^{83)}$ to examine the risk of thyroid cancer with respect to residing near NPP. The authors found no significant association: standardized incidence rate $(\mathrm{SIR})=0.98(95 \%$ $\mathrm{Cl}, 0.87-1.11)$, standardized mortality rate (SMR) $=0.80$ $(95 \% \mathrm{Cl}, 0.62-1.04)$. But sensitivity analysis by exposure definition demonstrated that residing less than $20 \mathrm{~km}$ from NPP was connected to significant increase in the risk of thyroid cancer, $O R=1.75(95 \% \mathrm{Cl}$, 1.17-2.2) ${ }^{83)} \mathrm{A}$ thyroid cancer mortality increase has been described for British Workers at Sellafield multi-function nuclear site. ${ }^{84)}$

\section{New Observations from the Fukushima Nuclear Accident}

A new challenge to explore the carcinogenic effect of ionizing radiation on thyroid cancer is the Fukushima Daiichi NPP accident. ${ }^{85)}$ A large-scale thyroid ultrasound examination (TUE) survey started in 2011 for children and adolescents aged 18 years or younger at the time of the accident. Large-scale ultrasound mass screening in Fukushima Prefecture detected unexpected high thyroid cancer prevalence in young subjects. For comparison, some researchers in postChernobyl studies found that thyroid cancer incidence may rise by a factor of $3-7$, which may be at least partially interpreted by screening or increased 
Risk Factors of Increasing Incidence of Thyroid Carcinoma

surveillance. $^{69,78,86,87)}$

According to Suzuki et al. in the TUE survey, ${ }^{88,89)}$ 300,476 subjects were included. In three rounds of screening survey 152 thyroid cancer cases were operated with average age of patients being 17.8 years. The average tumor size was $14.9 \mathrm{~mm}$ (among them $16.5 \%$ with tumor diameters $>2 \mathrm{~cm}$ ). Postoperative lymph node metastases, extra-thyroidal invasion, and pulmonary metastases were detected in $80.0 \%$, $42.1 \%$, and $2.6 \%$ of patients, respectively. Hemi-thyroidectomy was performed in $91.7 \%$, total thyroidectomy in $8.3 \%$, lymph node dissection of the central compartment in $84.8 \%$ and of the lateral compartment in $15.2 \%$ of all cases. It should be noted that lymph node metastases were visualized by ultrasound only in $19.3 \%$ cases. $^{88,89)}$ For comparison, the clinical data of 1078 post-Chernobyl pediatric patients 4-18 years of age at diagnosis with all types of PTC born before April 1, 1987 in Belarus operated in 68.6\% with total thyroidectomy, revealed mean tumor size of $14.4 \pm 10.6$ $\mathrm{mm}, \mathrm{N} 1$ stages with lymph node metastases in $73.7 \%$ and M1 stages with pulmonary metastases in $11.1 \%{ }^{90)}$ So interestingly, the percentage of patients needing thyroid surgery with lymph node metastases after Fukushima and Chernobyl was very similar (80\% vs. $74 \%)$.

The findings from the TUE elevated concerns among the medical community and residents of Fukushima that it could be related to the radiation accident at Daiichi NPP. ${ }^{91)}$ According to the studies reported, thyroid cancer cases in Fukushima survey cannot be directly associate with the effects of radiation, because 1) The thyroid doses in Fukushima with $<1$ $\mathrm{mSv}$ and maximum $50 \mathrm{mSv}$ were much lower than those in Chernobyl (median $300 \mathrm{mSv}$, 95\% of doses higher than $50 \mathrm{mSv}{ }^{.92)}$ 2) The period between exposure and detection of thyroid cancer in Fukushima was shorter as in Chernobyl with 4 years; 3) Thyroid cancer patients in Fukushima were much older than the Chernobyl children with mean age of 16 years and 8 years respectively. ${ }^{91,92)}$

On the other hand, it is understandable that concerns in the population and open questions of scientists about the "thyroid cancer epidemy" after the
Fukushima disaster continue to exist because it is unclear why such a high number of clinically relevant thyroid cancer cases with lymph node metastases is observed. According to Yamashita et al. ${ }^{91)}$ "further follow-up of the Fukushima cohort may provide unique insights into the incidence and natural history of PTC in young individuals including potential risk factors other than radiation".

\section{Other Endogenous and Exogenous Risk Factors or Confounders}

\section{Ethnicity, Heredity, Sex Effects/Hormones, Comorbidity}

The comprehensive interactive data set of Cancer in Five Continents ${ }^{93)}$ allows us to check for differences in the incidence and mortality of cancer related to regions and countries worldwide. The search for incidences in 2018 shows the well-known mass screening effect with incidences higher than 2-fold for Korea as compared to the rest of the world. The USA and Italy follow the incidence statistics as generally high-income countries. Within the USA, thyroid cancer incidence seems to lower in citizens of African or Hispanic origin. For Israel, thyroid cancer incidence seems to be higher in the Jewish population as compared to the non-Jewish population. These observations from the USA and Israel again are explainable by better access to medical care. Keane et al. ${ }^{94)}$ in a systematic review stated: "The variations amongst incidence and outcomes of thyroid cancer in racial groups are most likely a result of a number of interrelating factors, including genetic, environmental and modifiable lifestyle factors".

Individual susceptibility and heredity could increase the thyroid cancer risk. They include familial adenomatous polyposis (Gardner Syndrome), Carney complex type 1, Cowden syndrome and Werner syndrome. ${ }^{95)}$ Familial adenomatous polyposis could associate with $1-12 \%$ of the lifetime thyroid cancer risk, ${ }^{96)}$ in PTEN hamartoma tumor syndrome - with $35 \%{ }^{97)}$ In patients with DICER1 syndrome, the risk of 
developing thyroid cancer may be 16 times higher than in the population. ${ }^{98)}$

A strong association for susceptibility to thyroid cancer was disclosed for rs965513 (PTCSC2/FOXE1) in chromosome 9q22.33. ${ }^{99)}$ A genome-wide association study by Takahashi et al. ${ }^{100)}$ has shown a strong association of SNPs also in the FOXE1 region in Chernobyl cases of thyroid cancer, however no specific markers for radiation-induced thyroid cancer have been detected.

Many studies have proven, that thyroid cancer in women is more frequent than in men, with a ratio of around 1:1 before and 3:1 after puberty. This difference can be explained by hormone metabolism in the thyroid cancer etiology and possibly increased health awareness in women. ${ }^{101-103)} \mathrm{A}$ recent comprehensive review addressed the issue of estrogen activity in the thyroid was shown the strong proof for its capability to manage reactive-oxygen species (ROS) generation. The authors hypothesize that in women the higher thyroid cancer susceptibility could be due to higher ROS levels resulting in oxidative DNA damage accumulation. ${ }^{104)}$

Comorbidity and individual susceptibility may also be considered as etiologic factors of thyroid cancer. Recently a meta-analysis of twelve prospective observational studies by Liang et al. ${ }^{105)}$ showed association of benign thyroid diseases with thyroid cancer risk. The authors found that the pooled SIR of thyroid carcinoma was for goiter $7.65(95 \% \mathrm{Cl}, 6.94-8.37)$, for hyperthyroidism $5.96(95 \% \mathrm{Cl}, 1.88-10.03)$, for thyroiditis $3.25(95 \% \mathrm{Cl}, 1.62-4.89)$, and for all benign thyroid diseases $5.98(95 \% \mathrm{Cl}, 4.09-7.86) .{ }^{105)}$ The results of a Denmark Nationwide population-based registry study demonstrated an increased risk of thyroid cancer in patients with diagnosis of thyroiditis and hyperthyroidism that cannot be completely associated with greater medical surveillance. ${ }^{106)}$

Obesity is a well-described risk factor for thyroid cancer. ${ }^{107)}$ Obesity incidence has increased among US population 3-fold between 1960 and 2012, paralleling trends in thyroid cancer incidence. ${ }^{108)}$ The relation of obesity to thyroid cancer remains under discussion. Schmid et al. ${ }^{109)}$ conducted a meta-analysis of thyroid cancer risk and adiposity measures. The authors analyzed data on 12,199 thyroid cancer patients and found that the thyroid cancer risk in overweight persons is $25 \%$ greater and in individuals with obesity - 55\% greater than their normal weight peers. ${ }^{109)}$

\section{Diet (iodine), Life-style (smoking)}

Nutritional iodine deficiency could be one of the factors that might elucidate significant differences in thyroid cancer incidence in different areas and countries. ${ }^{58,110)}$ However, change of iodine intake in population does not effect the overall risk for thyroid cancer directly, but modification of iodine deficiency might shift the subtypes of thyroid cancer from follicular and anaplastic toward less malignant papillary forms. ${ }^{110)}$ Some studies demonstrated an interconnection between increasing thyroid cancer prevalence and increasing iodine intake levels in the population over the years since iodine supplementation began. ${ }^{111,112)}$ However no differences in two Hungarian regions with different iodine intake were shown in the autopsy study of Kovacs et al. ${ }^{113)}$

Recently Cao et al. ${ }^{114)}$ carried out a meta-analysis of 8 case-control studies (2213 cases; 2761 controls) to estimate the association between the thyroid cancer risk and iodine intake. The authors found that excess iodine intake $(>300 \mathrm{mg} / \mathrm{d})$ related to the reduced risk of thyroid cancer $(\mathrm{OR}=0.74,95 \% \mathrm{Cl}, 0.60-0.92)$ and was as a protective factor. ${ }^{114)}$ Another meta-analysis by Lee et al. ${ }^{115)}$ of association between iodine intake and prevalence of PTC has demonstrated a higher iodine exposure in thyroid cancer patients compared with controls, especially in regions with high iodine supply. The authors found a positive association between the thyroid cancer risk and iodine exposure. The OR for high iodine exposure and the thyroid cancer risk was 1.41 (95\% Cl, 1.05-1.90) and even higher in high iodinated regions - $(\mathrm{OR}=2.20,95 \% \mathrm{Cl}, 1.38-$ 3.48). ${ }^{115)}$ These studies demonstrate considerable controversy between iodine intake and PTC risk.

Several studies have report a protective effect of smoking. According to Kitahara et al. ${ }^{116)}$ "current smoking consistently has been associated with a 30\% to $40 \%$ reduction in thyroid cancer risk in USA, in- 
Risk Factors of Increasing Incidence of Thyroid Carcinoma

dependent of obesity and other risk factors". The "protective" effect of smoking is stronger and dose related in current smokers, may be associated with estrogen metabolism. ${ }^{117-119)}$ Smoking is significantly associated with lower exhaled nitric oxide level possibly reducing the risk for thyroid related to nitrate/nitrite, see section 5.5. ${ }^{120,121)}$ To summarize, obesity has to be considered as a proven thyroid cancer risk factor whereas the role of smoking as protective factor remains to be corroborated.

\section{Risk Factors of the Natural Environment}

It has been described that some environment factors, like volcanic activity, could be associated with increased thyroid cancer risk. Also exposure to heavy metals and/or natural radioactivity may play a role. For instance, in volcanic area of the Mount Etna the thyroid cancer incidence is two times higher than the rest of Sicily, and mainly the papillary type of thyroid cancer is elevated. ${ }^{5,122-124)}$ High figures of thyroid cancer are registered in Iceland and Hawaii and a possible association with volcanic activity has been suggested. ${ }^{123-125)}$ In volcanic areas of the Pacific Islands, the agestandardized rate of the thyroid cancer incidence is particularly increased, in French Polynesia it was 24.6/100,000 women and in New Caledonia it reached 71.4/100,000 Melanesian women during 19851999. ${ }^{126)}$

\section{Endocrine Disruptors}

In recent decades, the population is increasingly exposed to endocrine disruptors, environmental pollutants like pesticides, asbestos, benzene, polychlorinated biphenyls (PCB), formaldehyde, polyhalogenated aromatic hydrocarbons (PHAHs), bisphenol A (BPA), and nitrates. Many of these chemicals could be carcinogens. For example, flame retardants consisting of polybrominated diphenyl ethers (PBDEs) may stimulate precancerous proliferation of thyroid cell. Endocrine disruptors can mimic, block or overstimulate naturally occurring hormones (thyroid hormones, estrogens, and androgens) or their receptors. Exposure to endocrine disruptors during intrauterine life and early childhood could promote thyroid cell mutagenesis. ${ }^{6,127)}$ New data from the US Agricultural Health Study reveal that thyroid cancer risk is elevated in agricultural workers using pesticides. ${ }^{128)}$

\section{Nitrate and Radiation as Possible Interacting Carcinogens}

Besides the radiation exposure, nitrates are discussed as a risk factor for developing thyroid cancer. ${ }^{129-131)}$ Environmental endocrine effects caused by nitrates have received increasing attention over the last 15 years. Nitrate can interfere with steroid and thyroid hormone homeostasis, reproductive and developmental endpoints as environmental endocrine disruptor. ${ }^{132)}$ Over the past hundred years, human activity through the use of nitrate fertilizers and the combustion of fossil fuels have doubled the natural nitrogen level onto land. ${ }^{129,133-135)}$ In the United States the maximum contaminant level (MCL) of public drinking water for nitrate is $10 \mathrm{mg} / \mathrm{L}$ as nitrate-nitrogen (NO3-N). In accordance with the World Health Organization (WHO) guideline, nitrate standards for drinking water are 50 $\mathrm{mg} / \mathrm{L}$ as NO3 or $11.3 \mathrm{mg} / \mathrm{L} \mathrm{NO3-N}$. These nitrate regulations have been developed for the prevention of infant methemoglobinemia; however cancer and other adverse health consequences were not considered. ${ }^{129)}$

Also Ward et al. ${ }^{136)}$ studied the risk of thyroid cancer in lowa's agricultural areas with higher average nitrate levels (>5 mg/l nitrate- $\mathrm{N}$ ) in public water supplies. The authors found that RR for thyroid cancer of 2.6 (95\% Cl, 1.1-6.2) was increased with consumption of water above $5 \mathrm{mg} / \mathrm{L}$ nitrate- $\mathrm{N}$ for time longer than 5 years. ${ }^{136)}$ It should be stressed that the carcinogenic effect of nitrate in drinking water is higher than that of nitrate in food because of faster resorption of water and lack of protective antioxidants as e.g. vitamin C, which are available in vegetables and fruit. ${ }^{129)} \mathrm{A}$ meta-analysis of Xie et al. ${ }^{137)}$ included these studies and stressed the observation that dietary nitrate is a significant risk factor for developing thyroid cancer. Exposure-based assessment of cancer risk due to nitrate in United States drinking water showed that it could be from 0.8 to 2 percent of the annual US thyroid cancer cases, leading to an additional 369-1047 thyroid cancers. ${ }^{138)}$ 
Orita et al. ${ }^{139)}$ performed in Kawauchi village (Fukushima prefecture, Japan) an examination of nitrate concentrations in drinking water. The average nitrate-N level was $0.62 \mathrm{mg} / \mathrm{L}(0.20-2.51 \mathrm{mg} / \mathrm{L})$, which was in the normal range. ${ }^{139)}$ The authors concluded that the examinations of dietary nitrate intake also are required for better understanding of the situation with the increased incidence of thyroid cancer in Fukushima. ${ }^{139)}$

Data published from our group demonstrated a synergetic effect of nitrate in drinking water and exposure to radioiodine after the Chernobyl accident on the prevalence of childhood thyroid cancer in Belarus. In Belarus, from 1960 to 1990, the average nitrate level in drinking water multiplied about 40-fold, from 1.1 to $41.6 \mathrm{mg} / \mathrm{L}$. It is related to the increase in usage of nitrogen fertilizers from 4 to $92 \mathrm{~kg} /$ hectare. ${ }^{130,131)}$ Our study ${ }^{130)}$ demonstrated that in Belarus children from Gomel region received the highest thyroid doses after Chernobyl (320 mGy). The incidence of childhood radio induced thyroid cancer (11 per 100,000 PY) was the highest exactly in Gomel region. However, the incidence also increased in the Brest region (5.51 per 100,000 PY), where the thyroid doses were lower (51 $\mathrm{mGy}$ ), than in Mogilev region (65 mGy, with incidence 1.50 per 100,000 PY). A reasonable explanation could be addressed to the level of nitrates in drinking water.
The highest in Belarus was in Brest region - $185 \mathrm{mg} / \mathrm{l}$, and the lowest, practically within the normal range in Mogilev region - $40 \mathrm{mg} / \mathrm{l}$. The thyroid cancer incidence was significantly corresponded to the radiation dose $(p=0.029)$. The effect of radiation was altered significantly by a local level of nitrates in drinking water $(p=0.004){ }^{130)}$ Moreover the prevalence of radiation induced thyroid cancer among rural children of most contaminated areas (Gomel, Brest, Mogilev) with higher thyroid doses and higher pollution of drinking water with nitrates was significantly elevated in comparison with urban $(p<0.001) .{ }^{140}$

In addition, we analyzed the data gathered from different screening programs among children after Chernobyl accident in 1990-2005. The prevalence of thyroid cancer in radiation exposed children ranged $0.2-0.6 \%$ in Gomel with highest thyroid dose, $0.3 \%$ in Brest with lowest thyroid dose and only $0.008 \%$ in Mogilev administrative region with a dose similar to, but slightly higher than in Brest. In this way, the analysis of ultrasound screening program results in Belarus showed that the difference in the thyroid cancer prevalence between Brest and Mogilev regions may be related to local environmental condition. ${ }^{130}$

Based on our own experiences and literature data, we hypostasize that the risk for developing thyroid cancer could be addressed to the coexistence of sev-

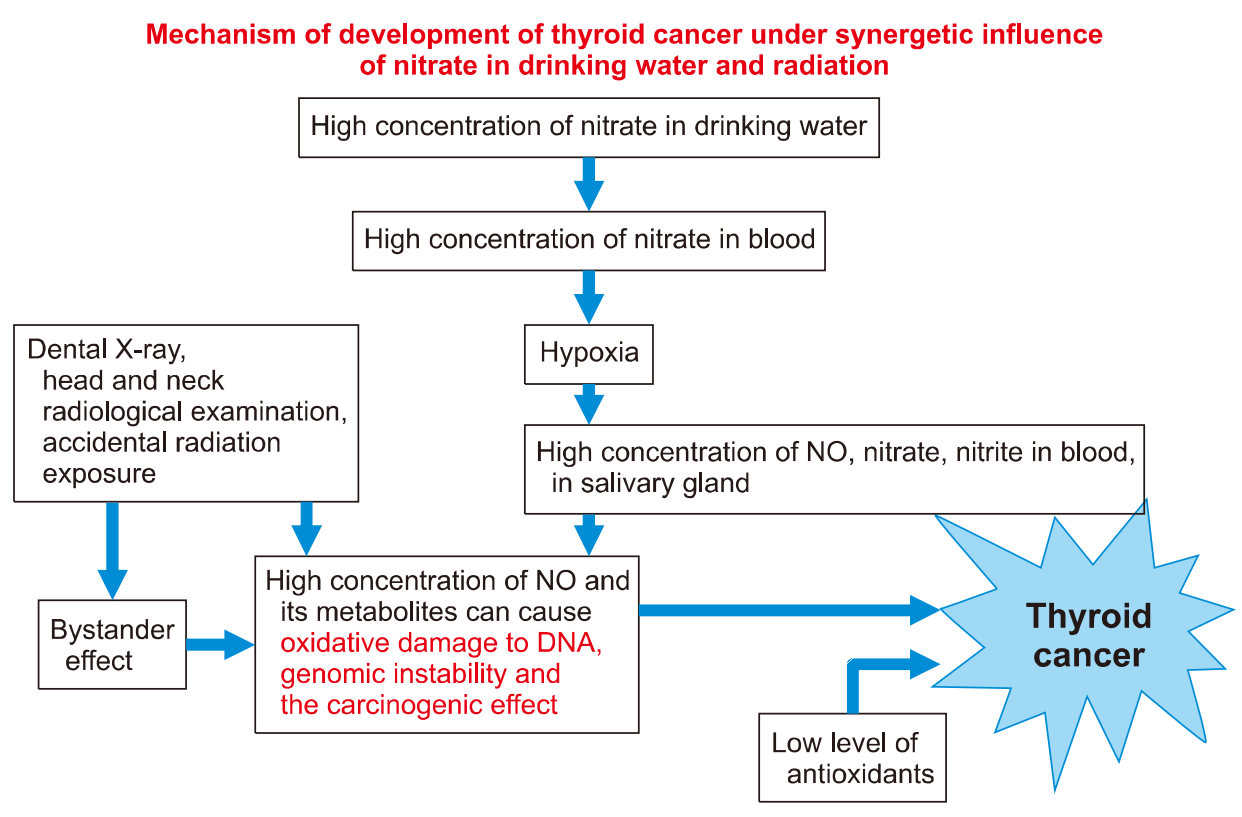

Fig. 1. Scheme of combined effects of nitrate and radiation exposure on development of thyroid cancer. Based on data in Ward et al. $^{129)}$ and Drozd et al. ${ }^{130,131)}$ 
Risk Factors of Increasing Incidence of Thyroid Carcinoma

eral circumstances (Fig. 1): 1) the use of water with an excessive nitrate contamination leads to the development of hypoxia in the blood, especially in children, changes metabolism towards nitrite production and NO, which can cause genomic instability and carcinogenic effect; 2) Dental $X$-ray, head and neck radiological examination, accidental radiation exposure of thyroid and salivary glands could also lead to increased plasma concentration of NO; and 3) if both of these processes coincide, the substantially increased NO levels presumably enhance the carcinogenic effect of the radiation. ${ }^{131)}$

\section{Strategies for Primary Prevention}

Without any doubt, thyroid cancer incidence is increasing with approximately $3-5 \%$ per year in different countries of the world during the last 3 decades. However, it appears in our opinion, that only $50-60 \%$ of this rise can be interpreted by screening only. It is likely that increasing exposure to risk factors like medical radiation, life-style change, and environmental pollutants are considered to play an important role as well.
For the clinician, a simple approach for primary prevention of thyroid cancer is to refer the patient for a radiological examination applying ionizing radiation with exposure of the head and neck region only if the indication is justified according to the International Committee for Radiological Protection ${ }^{141)}$ following the principle "Choosing Wisely" of the American College of Radiologists ${ }^{142)}$ or other expert committees. In children and adolescents, this justification that has to be approved by the radiologist is of exceptional importance. Generally, the radiologist should apply low dose CT protocols and image reconstruction procedures up-to-date as well as thyroid shielding for dental radiography and head and neck $\mathrm{CT}^{34)}$

In case of a nuclear emergency, attention has to be paid for immediate withdrawal of contaminated food and drink as well as iodine thyroid blocking, especially in vulnerable members of the population such as children, pregnant or breastfeeding women. ${ }^{143)}$ Mass ultrasound screening for thyroid cancer is not recommended, however programs for individual long-term monitoring should be considered for higher risk individuals (depending on doses, age and other risk factors). ${ }^{1-3)}$

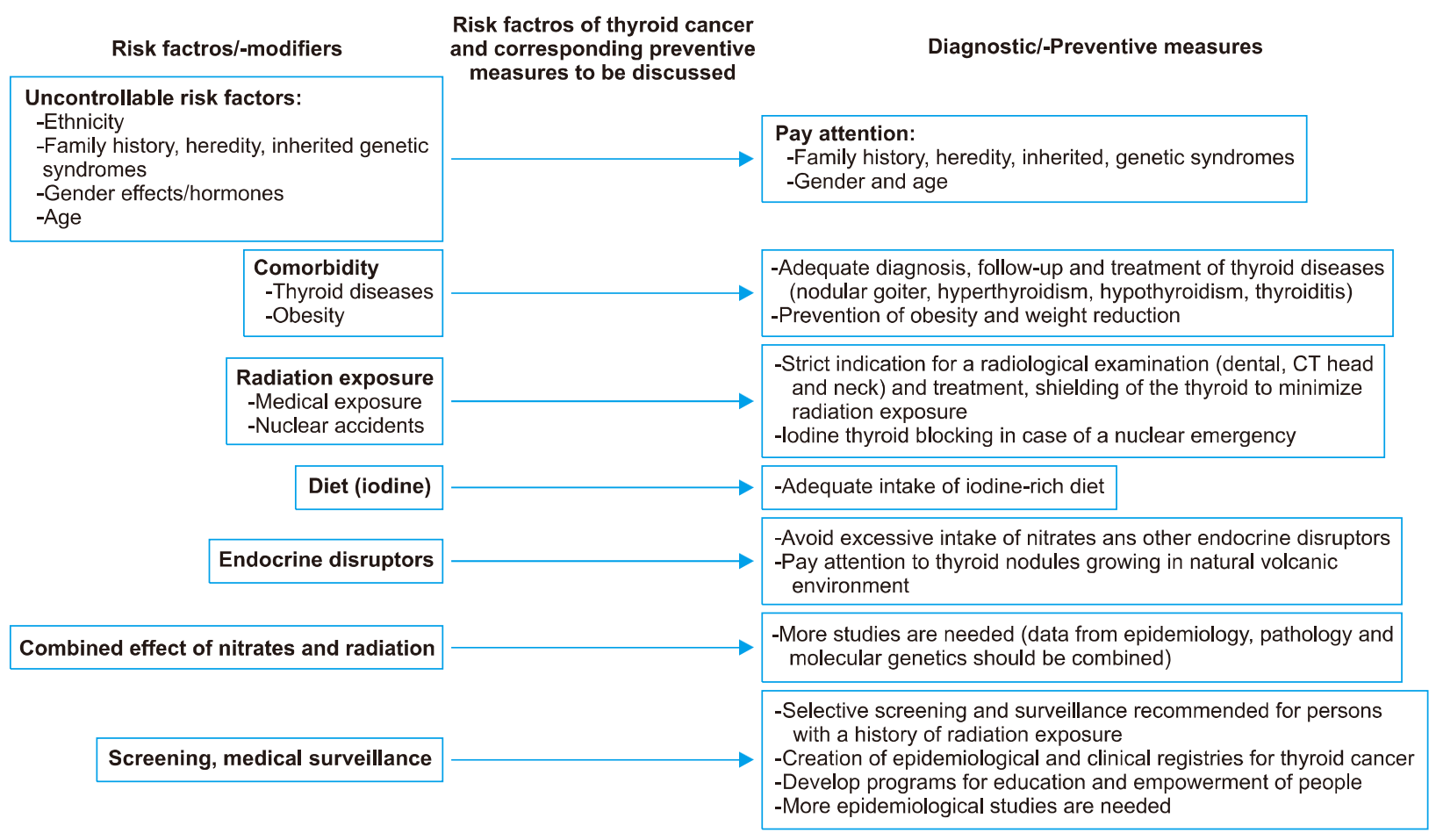

Fig. 2. Risk factors for thyroid cancer and corresponding preventive measures to be discussed. Based on data in Haugen et al., ${ }^{1)}$ WHO documents, ${ }^{3,6,143)}$ Drozd et al., ${ }^{130,131)}$ ICRP document ${ }^{141)}$ and Sinnott et al. ${ }^{34)}$ 
The World Health Organization recommends creating and supporting national cancer registries. Such systems allow keeping records of trends in disease incidence and geographical variation. This is especially important in the case an emergency. WHO also encourages to educate, and engages people to have a more active position in their own health. ${ }^{3)}$

To develop effective preventive measures, more research is needed to better understand the role of endocrine disruptors, specifically on combined effects of nitrates and radiation in thyroid carcinogenesis processes. Based on the known risk factors for thyroid cancer, we tried to present an algorithm that can help clinicians in the early diagnosis and development of preventive measures (Fig. 2).

Generally, the issue of overdiagnosis of thyroid cancer should be discussed more thoroughly. As shown here, a substantial proportion of children operated on for thyroid cancer after the Fukushima disaster - irrespective from radiation as a risk factor - suffers from clinically relevant disease, which cannot be brushed aside with overdiagnosis. Also more research is required to understand which factors predict the behavior of thyroid cancer and classify it as aggressive or indolent. Such research will allow us to avoid overdiagnosis and overtreatment. Better understanding of the influence of various risk factors on the induction of thyroid cancer will help clinicians develop effective strategies for disease prevention.

\section{Acknowledgments}

We thank Prof. Peter Kopp for a critical review with fruitful discussions and valuable comments and suggestions.

\section{Author Contribution}

VD, DIB, and CR contributed to the conception, collected the studies, discussed, and wrote the manuscript.

\section{Conflicts of Interest}

The authors declare that the study was performed in the absence of any financial or commercial relationship that may be interpreted as a potential conflict of interest.

\section{Orcid}

Valentina Drozd: https://orcid.org/0000-0003-2911-037X Daniel I. Branovan: https://orcid.org/0000-0001-5069-7297 Christoph Reiners: https://orcid.org/0000-0001-8093-8725

\section{References}

1) Haugen BR, Alexander EK, Bible KC, Doherty GM, Mandel SJ, Nikiforov YE, et al. 2015 American Thyroid Association management guidelines for adult patients with thyroid nodules and differentiated thyroid cancer: the American Thyroid Association guidelines task force on thyroid nodules and differentiated thyroid cancer. Thyroid 2016;26(1):1-133.

2) US Preventive Services Task Force; Bibbins-Domingo K, Grossman DC, Curry SJ, Barry MJ, Davidson KW, et al. Screening for thyroid cancer: US Preventive Services Task Force recommendation statement. JAMA 2017;317(18):1882-7.

3) International Agency for Research on Cancer. Thyroid health monitoring after nuclear accidents. IARC Technical Publications No. 46. Lyon, France: IARC Publications; 2018.

4) Merlo DF, Filiberti R, Kobernus M, Bartonova A, Gamulin $\mathrm{M}$, Ferencic $\mathrm{Z}$, et al. Cancer risk and the complexity of the interactions between environmental and host factors: HENVINET interactive diagrams as simple tools for exploring and understanding the scientific evidence. Environ Health 2012;11 Suppl 1:S9.

5) Pellegriti G, Frasca F, Regalbuto C, Squatrito S, Vigneri R Worldwide increasing incidence of thyroid cancer: update on epidemiology and risk factors. J Cancer Epidemiol 2013;2013: 965212.

6) Bergman A, Heindel JJ, Jobling S, Kidd KA, Zoeller RT. State of the science of endocrine disrupting chemicals - 2012. World Health Organization, United Nations Environment Programme (WHO-UNEP); 2012.

7) United Nations Scientific Committee on the Effects of Atomic Radiation. Sources and effects of ionizing radiation. UNSCEAR 2008 report to the general assembly with scientific annexes. Annex D: Health effects due to radiation from the Chernobyl accident. New York: United Nations; 2011. p.219.

8) Chen AY, Jemal A, Ward EM. Increasing incidence of differentiated thyroid cancer in the United States, 1988-2005. Cancer 2009;115(16):3801-7.

9) Ahn HS, Welch HG. South Korea's thyroid-cancer "epidemic"-- 
Risk Factors of Increasing Incidence of Thyroid Carcinoma

turning the tide. N Engl J Med 2015;373(24):2389-90.

10) Vaccarella S, Dal Maso L, Laversanne M, Bray F, Plummer $\mathrm{M}$, Franceschi S. The impact of diagnostic changes on the rise in thyroid cancer incidence: a population-based study in selected high-resource countries. Thyroid 2015;25(10):1127-36.

11) Lim H, Devesa SS, Sosa JA, Check D, Kitahara CM. Trends in thyroid cancer incidence and mortality in the United States, 1974-2013. JAMA 2017;317(13):1338-48.

12) Bray F, Colombet M, Mery L, Piñeros M, Znaor A, Zanetti $\mathrm{R}$, et al. Cancer incidence in five continents, Vol. XI (electronic version). Lyon, France: International Agency for Research on Cancer; 2017. Available from: http://ci5.iarc.fr

13) Qian ZJ, Jin MC, Meister KD, Megwalu UC. Pediatric thyroid cancer incidence and mortality trends in the United States, 1973-2013. JAMA Otolaryngol Head Neck Surg 2019; 145(7):617-23.

14) McNally RJ, Blakey K, James PW, Gomez Pozo B, Basta NO, Hale J. Increasing incidence of thyroid cancer in Great Britain, 1976-2005: age-period-cohort analysis. Eur J Epidemiol 2012;27(8):615-22.

15) Cho YY, Jang HW, Joung JY, Park SM, Jeong DJ, Kim SW, et al. Trends in thyroid cancer incidence in Korean Children (1999-2012) based on palpation and nompalpation detection methods. Eur Thyroid J 2015;4(4):252-9.

16) Fukunaga FH, Yatani R. Geographic pathology of occult thyroid carcinomas. Cancer 1975;36(3):1095-9.

17) Harach HR, Franssila KO, Wasenius VM. Occult papillary carcinoma of the thyroid. A "normal" finding in Finland. A systematic autopsy study. Cancer 1985;56(3):531-8.

18) Furuya-Kanamori L, Bell KJL, Clark J, Glasziou P, Doi SAR. Prevalence of differentiated thyroid cancer in autopsy studies over six decades: a meta-analysis. J Clin Oncol 2016; 34(30):3672-9.

19) Ahn HS, Kim HJ, Welch HG. Korea's thyroid-cancer "epidemic"--screening and overdiagnosis. N Engl J Med 2014; 371(19):1765-7.

20) Ahn HS, Kim HJ, Kim KH, Lee YS, Han SJ, Kim Y, et al. Thyroid cancer screening in South Korea increases detection of papillary cancers with no impact on other subtypes or thyroid cancer mortality. Thyroid 2016;26(11):1535-40.

21) Choi YM, Kim WG, Kwon H, Jeon MJ, Han M, Kim TY, et al. Changes in standardized mortality rates from thyroid cancer in Korea between 1985 and 2015: analysis of Korean national data. Cancer 2017;123(24):4808-14.

22) Jeon MJ, Kim HK, Kim EH, Kim ES, Yi HS, Kim TY, et al. Decreasing disease-specific mortality of differentiated thyroid cancer in Korea: a multicenter cohort study. Thyroid 2018;28(9):1121-7.

23) Sprague BL, Warren Andersen S, Trentham-Dietz A. Thyroid cancer incidence and socioeconomic indicators of health care access. Cancer Causes Control 2008;19(6):585-93.

24) Morris LG, Sikora AG, Tosteson TD, Davies L. The increasing incidence of thyroid cancer: the influence of access to care. Thyroid 2013;23(7):885-91.

25) Udelsman R, Zhang Y. The epidemic of thyroid cancer in the United States: the role of endocrinologists and ultrasounds. Thyroid 2014;24(3):472-9.
26) Enewold L, Zhu K, Ron E, Marrogi AJ, Stojadinovic A, Peoples GE, et al. Rising thyroid cancer incidence in the United States by demographic and tumor characteristics, 1980-2005. Cancer Epidemiol Biomarkers Prev 2009;18(3): 784-91.

27) Pathak KA, Leslie WD, Klonisch TC, Nason RW. The changing face of thyroid cancer in a population-based cohort. Cancer Med 2013;2(4):537-44.

28) Lin JS, Bowles EJA, Williams SB, Morrison CC. Screening for thyroid cancer: updated evidence report and systematic review for the US Preventive Services Task Force. JAMA 2017;317(18):1888-903.

29) Jung YS, Oh CM, Kim Y, Jung KW, Ryu J, Won YJ. Long-term survival of patients with thyroid cancer according to the methods of tumor detection: a nationwide cohort study in Korea. PLoS One 2018;13(4):e0194743.

30) Ron E, Modan B, Preston D, Alfandary E, Stovall M, Boice JD Jr. Thyroid neoplasia following low-dose radiation in childhood. Radiat Res 1989;120(3):516-31.

31) Ron E, Lubin JH, Shore RE, Mabuchi K, Modan B, Pottern LM, et al. Thyroid cancer after exposure to external radiation: a pooled analysis of seven studies. Radiat Res 1995;141(3): 259-77.

32) Sigurdson AJ, Ronckers CM, Mertens AC, Stovall M, Smith SA, Liu Y, et al. Primary thyroid cancer after a first tumour in childhood (the Childhood Cancer Survivor Study): a nested case-control study. Lancet 2005;365(9476):2014-23.

33) NCRP Report No. 159. Risks to the thyroid from ionizing radiation. Bethesda, MD: National Council on Radiation Protection and Measurement; 2009.

34) Sinnott B, Ron E, Schneider AB. Exposing the thyroid to radiation: a review of its current extent, risks, and implications. Endocr Rev 2010;31(5):756-73.

35) Shore RE, Woodard E, Hildreth N, Dvoretsky P, Hempelmann L, Pasternack B. Thyroid tumors following thymus irradiation. J Natl Cancer Inst 1985;74(6):1177-84.

36) Favus MJ, Schneider AB, Stachura ME, Arnold JE, Ryo UY, Pinsky SM, et al. Thyroid cancer occurring as a late consequence of head-and-neck irradiation. Evaluation of 1056 patients. N Engl J Med 1976;294(19):1019-25.

37) United Nations Scientific Committee on the Effects of Atomic Radiation, UNSCEAR 2008 Report. Sources and effects of ionizing radiation. Volume I: Sources. Report to the general assembly with scientific annexes $A$ and B. Available from: http://www.unscear.org/docs/publications/2008/UNSCEAR_ 2008_Report_Vol.I.pdf

38) Veiga LH, Holmberg E, Anderson H, Pottern L, Sadetzki S, Adams MJ, et al. Thyroid cancer after childhood exposure to external radiation: an updated pooled analysis of 12 studies. Radiat Res 2016;185(5):473-84.

39) Mettler FA Jr, Thomadsen BR, Bhargavan M, Gilley DB, Gray JE, Lipoti JA, et al. Medical radiation exposure in the U.S. in 2006: preliminary results. Health Phys 2008;95(5): 502-7.

40) Mettler FA Jr, Mahesh M, Bhargavan-Chatfield M, Chambers CE, Elee JG, Frush DP, et al. Patient exposure from radiologic and nuclear medicine procedures in the United 
States: procedure volume and effective dose for the period 2006-2016. Radiology 2020;295(2):418-27.

41) NCRP Report No. 160. Ionizing radiation exposure of the population of the United States. Bethesda, MD: the National Council on Radiation Protection and Measurement; 2009.

42) das Bundesamt für Strahlenschutz. Available from: https:// www.bfs.de/EN/topics/ion/radiation-protection/limit-values/limitvalues_node.html [cited October 12, 2020]

43) Leswick DA, Hunt MM, Webster ST, Fladeland DA. Thyroid shields versus z-axis automatic tube current modulation for dose reduction at neck CT. Radiology 2008;249(2):572-80.

44) Tipnis SV, Spampinato MV, Hungerford J, Huda W. Thyroid doses and risks to adult patients undergoing neck $C T$ examinations. AJR Am J Roentgenol 2015;204(5):1064-8.

45) Abuzaid MM, Elshami W, Haneef C, Alyafei S. Thyroid shield during brain CT scan: dose reduction and image quality evaluation. Imaging Med 2017;9(3):45-8.

46) Visweswaran S, Kanagaraj K, Joseph S, Perumal V. Medical imaging: contribution toward background radiation and human exposure. J Radiat Cancer Res 2018;9(4):177-82.

47) Dawson P, Punwani S. The thyroid dose burden in medical imaging A re-examination. Eur J Radiol 2009;69(1):74-9.

48) Zhang Y, Chen Y, Huang H, Sandler J, Dai M, Ma S, et al. Diagnostic radiography exposure increases the risk for thyroid microcarcinoma: a population-based case-control study. Eur J Cancer Prev 2015;24(5):439-46.

49) Hong JY, Han K, Jung JH, Kim JS. Association of exposure to diagnostic low-dose ionizing radiation with risk of cancer among youths in South Korea. JAMA Netw Open 2019;2(9): e1910584.

50) Memon A, Godward S, Williams D, Siddique I, Al-Saleh K. Dental $x$-rays and the risk of thyroid cancer: a case-control study. Acta Oncol 2010;49(4):447-53.

51) Wingren G, Hallquist A, Hardell L. Diagnostic X-ray exposure and female papillary thyroid cancer: a pooled analysis of two Swedish studies. Eur J Cancer Prev 1997;6(6):550-6.

52) Preston-Martin S, Thomas DC, White SC, Cohen D. Prior exposure to medical and dental $x$-rays related to tumors of the parotid gland. J Natl Cancer Inst 1988;80(12):943-9.

53) Preston-Martin S, White SC. Brain and salivary gland tumors related to prior dental radiography: implications for current practice. J Am Dent Assoc 1990;120(2):151-8.

54) Hallquist A, Hardell L, Degerman A, Boquist L. Occupational exposures and thyroid cancer: results of a case-control study. Eur J Cancer Prev 1993;2(4):345-9.

55) Zabel EW, Alexander BH, Mongin SJ, Doody MM, Sigurdson AJ, Linet MS, et al. Thyroid cancer and employment as a radiologic technologist. Int J Cancer 2006;119(8):1940-5.

56) American Dental Association Council on Scientific Affairs. The use of dental radiographs: update and recommendations. J Am Dent Assoc 2006;137(9):1304-12.

57) Han MA, Kim JH. Diagnostic X-ray exposure and thyroid cancer risk: systematic review and meta-analysis. Thyroid 2018;28(2):220-8.

58) Nagataki S, Nystrom E. Epidemiology and primary prevention of thyroid cancer. Thyroid 2002;12(10):889-96.

59) Socolow EL, Hashizume A, Neriishi S, Niitani R. Thyroid carcinoma in man after exposure to ionizing radiation. A summary of the findings in Hiroshima and Nagasaki. N Engl J Med 1963;268:406-10.

60) Furukawa K, Preston D, Funamoto S, Yonehara S, Ito M, Tokuoka S, et al. Long-term trend of thyroid cancer risk among Japanese atomic-bomb survivors: 60 years after exposure. Int J Cancer 2013;132(5):1222-6.

61) Thompson DE, Mabuchi K, Ron E, Soda M, Tokunaga M, Ochikubo S, et al. Cancer incidence in atomic bomb survivors. Part II: Solid tumors, 1958-1987. Radiat Res 1994;137(2 Suppl):S17-67.

62) Lund E, Galanti MR. Incidence of thyroid cancer in Scandinavia following fallout from atomic bomb testing: an analysis of birth cohorts. Cancer Causes Control 1999;10(3): 181-7.

63) WHO. 1986-2016: Chernobyl at 30. An update. 2016. Available from: http://www.who.int/ionizing radiation/chernobyl/ Chernobyl-update.pdf?ua $=1$.

64) Hatch M, Cardis E. Somatic health effects of Chernobyl: 30 years on. Eur J Epidemiol 2017;32(12):1047-54.

65) Kazakov VS, Demidchik EP, Astakhova LN. Thyroid cancer after Chernobyl. Nature 1992;359(6390):21.

66) Drozd VM, Astakhova LN, Polyanskaya ON, Kobzev VF, Nalivko AS, Tolkachev YV. Ultrasonic diagnostics of thyroid pathology in children and adolescents affected by radionuclides. Proceedings of the 6th International Congress on Interventional Ultrasound. University of Copenhagen: Denmark; 1993. p.110-1.

67) Cardis E, Kesminiene A, Ivanov V, Malakhova I, Shibata $\mathrm{Y}$, Khrouch V, et al. Risk of thyroid cancer after exposure to 1311 in childhood. J Natl Cancer Inst 2005;97(10):724-32.

68) Jacob P, Bogdanova TI, Buglova E, Chepurniy M, Demidchik Y, Gavrilin Y, et al. Thyroid cancer among Ukrainians and Belarusians who were children or adolescents at the time of the Chernobyl accident. I Radiol Prot 2006; 26(1):51-67.

69) Jacob P, Bogdanova TI, Buglova E, Chepurniy M, Demidchik Y, Gavrilin Y, et al. Thyroid cancer risk in areas of Ukraine and Belarus affected by the Chernobyl accident. Radiat Res 2006;165(1):1-8.

70) Davis S, Stepanenko V, Rivkind N, Kopecky KJ, Voilleque $\mathrm{P}$, Shakhtarin V, et al. Risk of thyroid cancer in the Bryansk Oblast of the Russian Federation after the Chernobyl Power Station accident. Radiat Res 2004;162(3):241-8.

71) Astakhova LN, Anspaugh LR, Beebe GW, Bouville A, Drozdovitch VV, Garber V, et al. Chernobyl-related thyroid cancer in children of Belarus: a case-control study. Radiat Res 1998;150(3):349-56.

72) Tronko MD, Howe GR, Bogdanova TI, Bouville AC, Epstein $\mathrm{OV}$, Brill $\mathrm{AB}$, et al. A cohort study of thyroid cancer and other thyroid diseases after the chornobyl accident: thyroid cancer in Ukraine detected during first screening. J Natl Cancer Inst 2006;98(13):897-903.

73) Little MP, Kukush AG, Masiuk SV, Shklyar S, Carroll RJ, Lubin $\mathrm{JH}$, et al. Impact of uncertainties in exposure assessment on estimates of thyroid cancer risk among Ukrainian children and adolescents exposed from the Chernobyl accident. PLoS One 2014;9(1):e85723. 
Risk Factors of Increasing Incidence of Thyroid Carcinoma

74) Zablotska LB, Ron E, Rozhko AV, Hatch M, Polyanskaya $\mathrm{ON}$, Brenner AV, et al. Thyroid cancer risk in Belarus among children and adolescents exposed to radioiodine after the Chornobyl accident. Br J Cancer 2011;104(1):181-7.

75) Zablotska LB, Nadyrov EA, Rozhko AV, Gong Z, Polyanskaya ON, McConnell RJ, et al. Analysis of thyroid malignant pathologic findings identified during 3 rounds of screening (1997-2008) of a cohort of children and adolescents from belarus exposed to radioiodines after the Chernobyl accident. Cancer 2015;121(3):457-66.

76) World Health Organization. Health consequences of the Chernobyl accident: results of the IPHECA pilot projects and related national programmes: scientific report. Geneva: WHO Press; 1996. p.519.

77) International Commission on Radiological Protection. Application of the Commission's recommendations for the protection of people in emergency exposure situations. ICRP Publication 109. Ann ICRP 2009;39(1).

78) Kaiser JC, Jacob P, Blettner M, Vavilov S. Screening effects in risk studies of thyroid cancer after the Chernobyl accident. Radiat Environ Biophys 2009;48(2):169-79.

79) Mangano JJ. Geographic variation in U.S. thyroid cancer incidence and a cluster near nuclear reactors in New Jersey, New York, and Pennsylvania. Int J Health Serv 2009;39(4): 643-61.

80) Levin RJ, De Simone NF, Slotkin JF, Henson BL. Incidence of thyroid cancer surrounding three mile island nuclear facility: the 30-year follow-up. Laryngoscope 2013;123(8):2064-71.

81) Desbiolles A, Roudier C, Goria S, Stempfelet M, Kairo C, Quintin $\mathrm{C}$, et al. Cancer incidence in adults living in the vicinity of nuclear power plants in France, based on data from the French Network of Cancer Registries. Int J Cancer 2018;142(5):899-909.

82) Davis S, Kopecky KJ, Hamilton TE, Onstad LE, King BL, Saporito MS, et al. Hanford thyroid disease study final report. Fred Hutchinson Cancer Research Center, Seattle, Washington; 2002. Available from: http://www.cdc.gov/nceh/radiation/hanford/ htdsweb/pdf/htdsreport.pdf

83) Kim J, Bang Y, Lee WJ. Living near nuclear power plants and thyroid cancer risk: a systematic review and meta-analysis. Environ Int 2016;87:42-8.

84) Douglas AJ, Omar RZ, Smith PG. Cancer mortality and morbidity among workers at the Sellafield plant of British Nuclear Fuels. Br J Cancer 1994;70(6):1232-43.

85) International Atomic Energy Agency. The Fukushima Daiichi accident; 2015. Available from: http://www-pub.iaea.org/books/ IAEABooks/10962/The-Fukushima-Daiichi-Accident.

86) Ivanov VK, Kashcheev VV, Chekin SY, Maksioutov MA, Tumanov KA, Vlasov OK, et al. Radiation-epidemiological studies of thyroid cancer incidence in Russia after the Chernobyl accident (estimation of radiation risks, 1991-2008 follow-up period). Radiat Prot Dosimetry 2012;151(3):489-99.

87) Likhtarov I, Kovgan L, Vavilov S, Chepurny M, Ron E, Lubin $\mathrm{J}$, et al. Post-Chernobyl thyroid cancers in Ukraine. Report 2: risk analysis. Radiat Res 2006;166(2):375-86.

88) Suzuki S, Matsumoto Y, Ookouchi C, Nakano K, Iwadate $\mathrm{M}$, Suzuki S, et al. The clinicopathological features of childhood and adolescent thyroid cancer in Fukushima after the Fukushima Daiichi nuclear power plant accident. Thyroid 2018; Supplement 1, (Poster 136).

89) Suzuki S, Bogdanova TI, Saenko VA, Hashimoto Y, Ito M, Iwadate M, et al. Histopathological analysis of papillary thyroid carcinoma detected during ultrasound screening examinations in Fukushima. Cancer Sci 2019;110(2):817-27.

90) Fridman M, Savva N, Krasko O, Mankovskaya S, Branovan $\mathrm{DI}$, Schmid $\mathrm{KW}$, et al. Initial presentation and late results of treatment of post-Chernobyl papillary thyroid carcinoma in children and adolescents of Belarus. J Clin Endocrinol Metab 2014;99(8):2932-41.

91) Yamashita S, Suzuki S, Suzuki S, Shimura H, Saenko V. Lessons from Fukushima: latest findings of thyroid cancer after the Fukushima Nuclear Power Plant accident. Thyroid 2018;28(1):11-22.

92) Kim E, Kurihara O, Kunishima N, Momose T, Ishikawa T, Akashi M. Internal thyroid doses to Fukushima residentsestimation and issues remaining. J Radiat Res 2016;57 Suppl 1:i118-i26.

93) International Agency for Research on Cancer. The comprehensive interactive data set of cancer incidence in five continents. Available from: http://ci5.iarc.fr/Default.aspx.

94) Keane E, Francis EC, Cathain EO, Rowley H. The role of race in thyroid cancer: systematic review. J Laryngol Otol 2017;131(6):480-6.

95) Nose V. Familial thyroid cancer: a review. Mod Pathol 2011;24 Suppl 2:S19-33.

96) Jasperson KW, Patel SG, Ahnen DJ. APC-associated polyposis conditions. In: Adam MP, Ardinger HH, Pagon RA, Wallace SE, Bean LJH, Stephens K, editors. GeneReviews. Seattle (WA), USA: University of Washington, Seattle. 2017. Available from: https://www.ncbi.nlm.nih.gov/books/NBK1345/.

97) Eng C. PTEN hamartoma tumor syndrome. In: Adam MP, Ardinger HH, Pagon RA, Wallace SE, Bean LJH, Stephens $K$, editors. GeneReviews Seattle (WA), USA: University of Washington, Seattle. 2001. Available from: https://www.ncbi. nlm.nih.gov/books/NBK1488/.

98) Khan NE, Bauer AJ, Schultz KAP, Doros L, Decastro RM, Ling A, et al. Quantification of thyroid cancer and multinodular goiter risk in the DICER1 syndrome: a family-based cohort study. J Clin Endocrinol Metab 2017;102(5):1614-22.

99) Gudmundsson J, Thorleifsson G, Sigurdsson JK, Stefansdottir L, Jonasson JG, Gudjonsson SA, et al. A genome-wide association study yields five novel thyroid cancer risk loci. Nat Commun 2017;8:14517.

100) Takahashi M, Saenko VA, Rogounovitch TI, Kawaguchi T, Drozd VM, Takigawa-Imamura $\mathrm{H}$, et al. The FOXE1 locus is a major genetic determinant for radiation-related thyroid carcinoma in Chernobyl. Hum Mol Genet 2010;19(12):2516-23.

101) McTiernan AM, Weiss NS, Daling JR. Incidence of thyroid cancer in women in relation to reproductive and hormonal factors. Am J Epidemiol 1984;120(3):423-35.

102) Levi F, Franceschi S, Gulie C, Negri E, La Vecchia C. Female thyroid cancer: the role of reproductive and hormonal factors in Switzerland. Oncology 1993;50(4):309-15.

103) Kilfoy BA, Devesa SS, Ward MH, Zhang Y, Rosenberg PS, 
Holford TR, et al. Gender is an age-specific effect modifier for papillary cancers of the thyroid gland. Cancer Epidemiol Biomarkers Prev 2009;18(4):1092-100.

104) Faria CC, Peixoto MS, Carvalho DP, Fortunato RS. The emerging role of estrogens in thyroid redox homeostasis and carcinogenesis. Oxid Med Cell Longev 2019;2019:2514312.

105) Liang L, Zheng XC, Hu MJ, Zhang Q, Wang SY, Huang F. Association of benign thyroid diseases with thyroid cancer risk: a meta-analysis of prospective observational studies. J Endocrinol Invest 2019;42(6):673-85.

106) Kitahara CM, Farkas DKR, Jorgensen JOL, Cronin-Fenton D, Sorensen HT. Benign thyroid diseases and risk of thyroid cancer: a nationwide cohort study. J Clin Endocrinol Metab 2018;103(6):2216-24.

107) Steele CB, Thomas CC, Henley SJ, Massetti GM, Galuska DA, Agurs-Collins T, et al. Vital signs: trends in incidence of cancers associated with overweight and obesity - United States, 2005-2014. MMWR Morb Mortal Wkly Rep 2017; 66(39):1052-8.

108) Centers for Disease Control and Prevention. 2017. Available from: https://www.cdc.gov.

109) Schmid D, Ricci C, Behrens G, Leitzmann MF. Adiposity and risk of thyroid cancer: a systematic review and meta-analysis. Obes Rev 2015;16(12):1042-54.

110) Zimmermann MB, Galetti V. Iodine intake as a risk factor for thyroid cancer: a comprehensive review of animal and human studies. Thyroid Res 2015;8:8.

111) Bacher-Stier C, Riccabona G, Totsch M, Kemmler G, Oberaigner W, Moncayo R. Incidence and clinical characteristics of thyroid carcinoma after iodine prophylaxis in an endemic goiter country. Thyroid 1997;7(5):733-41.

112) Lind P, Langsteger W, Molnar M, Gallowitsch HJ, Mikosch P, Gomez I. Epidemiology of thyroid diseases in iodine sufficiency. Thyroid 1998;8(12):1179-83.

113) Kovacs GL, Gonda G, Vadasz G, Ludmany E, Uhrin K, Gorombey Z, et al. Epidemiology of thyroid microcarcinoma found in autopsy series conducted in areas of different iodine intake. Thyroid 2005;15(2):152-7.

114) Cao LZ, Peng XD, Xie JP, Yang FH, Wen HL, Li S. The relationship between iodine intake and the risk of thyroid cancer: a meta-analysis. Medicine (Baltimore) 2017;96(20): e6734.

115) Lee JH, Hwang Y, Song RY, Yi JW, Yu HW, Kim SJ, et al. Relationship between iodine levels and papillary thyroid carcinoma: a systematic review and meta-analysis. Head Neck 2017;39(8):1711-8.

116) Kitahara CM, Linet MS, Beane Freeman LE, Check DP, Church TR, Park Y, et al. Cigarette smoking, alcohol intake, and thyroid cancer risk: a pooled analysis of five prospective studies in the United States. Cancer Causes Control 2012; 23(10):1615-24.

117) Galanti MR, Hansson L, Lund E, Bergstrom R, Grimelius L, Stalsberg H, et al. Reproductive history and cigarette smoking as risk factors for thyroid cancer in women: a population-based case-control study. Cancer Epidemiol Biomarkers Prev 1996; 5(6):425-31.

118) Rossing MA, Cushing KL, Voigt LF, Wicklund KG, Daling
JR. Risk of papillary thyroid cancer in women in relation to smoking and alcohol consumption. Epidemiology 2000;11(1): 49-54.

119) Kreiger N, Parkes R. Cigarette smoking and the risk of thyroid cancer. Eur J Cancer 2000;36(15):1969-73.

120) Karrasch S, Ernst K, Behr J, Heinrich J, Huber RM, Nowak $\mathrm{D}$, et al. Exhaled nitric oxide and influencing factors in a random population sample. Respir Med 2011;105(5):713-8.

121) Bommarito L, Migliore E, Bugiani M, Heffler E, Guida G, Bucca $\mathrm{C}$, et al. Exhaled nitric oxide in a population sample of adults. Respiration 2008;75(4):386-92.

122) Russo M, Malandrino P, Moleti M, D'Angelo A, Tavarelli M, Sapuppo G, et al. Thyroid cancer in the pediatric age in Sicily: influence of the volcanic environment. Anticancer Res 2017;37(3):1515-22.

123) Kung TM, Ng WL, Gibson JB. Volcanoes and carcinoma of the thyroid: a possible association. Arch Environ Health 1981;36(5):265-7.

124) Arnbjornsson E, Arnbjornsson A, Olafsson A. Thyroid cancer incidence in relation to volcanic activity. Arch Environ Health 1986;41(1):36-40.

125) Kristbjornsdottir A, Rafnsson V. Incidence of cancer among residents of high temperature geothermal areas in Iceland: a census based study 1981 to 2010. Environ Health 2012;11:73.

126) Clero E, Leux C, Brindel P, Truong T, Anger A, Teinturier $\mathrm{C}$, et al. Pooled analysis of two case-control studies in New Caledonia and French Polynesia of body mass index and differentiated thyroid cancer: the importance of body surface area. Thyroid 2010;20(11):1285-93.

127) Zhang Y, Guo GL, Han X, Zhu C, Kilfoy BA, Zhu Y, et al. Do polybrominated diphenyl ethers (PBDEs) increase the risk of thyroid cancer? Biosci Hypotheses 2008;1(4):195-9.

128) Lerro CC, Koutros S, Andreotti G, Sandler DP, Lynch CF, Louis LM, et al. Cancer incidence in the Agricultural Health Study after 20 years of follow-up. Cancer Causes Control 2019;30(4):311-22.

129) Ward MH, Jones RR, Brender JD, de Kok TM, Weyer PJ, Nolan BT, et al. Drinking water nitrate and human health: an updated review. Int J Environ Res Public Health 2018; 15(7):1557.

130) Drozd VM, Saenko VA, Brenner AV, Drozdovitch V, Pashkevich VI, Kudelsky AV, et al. Major factors affecting incidence of childhood thyroid cancer in Belarus after the Chernobyl accident: do nitrates in drinking water play a role? PLoS One 2015;10(9):e0137226.

131) Drozd VM, Branovan I, Shiglik N, Biko J, Reiners C. Thyroid cancer induction: nitrates as independent risk factors or risk modulators after radiation exposure, with a focus on the Chernobyl accident. Eur Thyroid J 2018;7(2):67-74.

132) Poulsen R, Cedergreen N, Hayes T, Hansen M. Nitrate: an environmental endocrine disruptor? A review of evidence and research needs. Environ Sci Technol 2018;52(7):3869-87.

133) Davidson EA, David MB, Galloway JN, Goodale CL, Haeuber R, Harrison JA, et al. Excess nitrogen in the U.S. environment: trends, risks, and solutions. Issues Ecol 2011;15: 1-16.

134) Vitousek PM, Aber JD, Howarth RW, Likens GE, Matson 


\section{Risk Factors of Increasing Incidence of Thyroid Carcinoma}

PA, Schindler DW, et al. Human alteration of the global nitrogen cycle: Sources and consequences. Ecol Appl 1997;7: $737-50$.

135) National Primary Drinking Water Regulations: Inorganic Chemicals. Available from: https://www.epa.gov/ground-water-anddrinking-water/national-primary-drinking-water-regulations

136) Ward MH, Kilfoy BA, Weyer PJ, Anderson KE, Folsom AR, Cerhan JR. Nitrate intake and the risk of thyroid cancer and thyroid disease. Epidemiology 2010;21(3):389-95.

137) Xie L, Mo M, Jia HX, Liang F, Yuan J, Zhu J. Association between dietary nitrate and nitrite intake and sitespecific cancer risk: evidence from observational studies. Oncotarget 2016; 7(35):56915-32.

138) Temkin A, Evans S, Manidis T, Campbell C, Naidenko OV. Exposure-based assessment and economic valuation of adverse birth outcomes and cancer risk due to nitrate in United States drinking water. Environ Res 2019;176:108442.

139) Orita M, Iyama K, Hayashida N, Mitsutake N, Suzuki S, Yamashita S, et al. Implication of Nitrate in Drinking Water in Kawauchi Village, Fukushima. Thyroid 2015;25(9):1064-5.
140) Drozd V, Branovan I, Platonova T, Shiglik N, Biko J, Reiners C. Nitrates impact on the prevalence of radiation induced thyroid cancer in rural and urban populations of Belarus among the children who were born before and after the Chernobyl accident. Program of the 88th Annual Meeting of the American Thyroid association. Washington DC, 2018. Thyroid 2018; Supplement 1:28. (Abstract).

141) Radiation and Your Patient: a Guide for Medical Practitioners. A web module produced by Committee 3 of the International Commission on Radiological Protection (ICRP). Available from: http://icrp.org/docs/Rad_for_GP_for_web.pdf.

142) American College of Radiology. Ten things physicians and patients should question. Available from: https://www. choosingwisely.org/societies/american-college-of-radiology/.

143) WHO. Iodine thyroid blocking: guidelines for use in planning for and responding to radiological and nuclear emergencies. Geneva, Switzerland: World Health Organization; $2017 a$. Available from: http://www.who.int/ionizing_radiation/pub_meet/ iodine-thyroid-blocking/en/ 